\title{
Characterization of DPP-IV inhibitory peptides using an in vitro cell culture model of the intestine
}

Ritian Jin, ${ }^{1,2,5}$ Jiaqi Shang, ${ }^{1,2,5}$ Xiangyu Teng, ${ }^{1,2,5}$ Ligang Zhang, ${ }^{1,2 *}$ Minhe Liao, ${ }^{1,2,5}$ Jiaxin Kang, ${ }^{1,2,5}$ Ran Meng, ${ }^{3}$ Dangfeng Wang, ${ }^{4}$ Haowei Ren, ${ }^{1,2,5 *}$ Ning Liu ${ }^{1,2,5 *}$

${ }^{1}$ College of Food Science, Northeast Agricultural University, Harbin, 150030, China

${ }^{2}$ Key Lab of Dairy Science, Ministry of Education, Northeast Agricultural University, Harbin, 150030, China

${ }^{3}$ Binhai Agricultural Research Institute of Hebei Academy of Agricultural and Forestry Science/Tangshan Key Laboratory of Plant Salt-Tolerance Research, Tangshan, 063200, China

${ }^{4}$ College of Food Science and Technology, Jiangnan University, Wuxi, 214122, China

${ }^{5}$ Harbin Tengning Technology Co., Ltd, Harbin, 150010, China

*Corresponding author; E-mail address: ningliuneau@outlook.com; Tel. +86 451 55191827; fax. +86 45155190340. 
Figure S1. The MS/MS spectrum of peptides identified in BL. (A) ATSG; (B) GPG; (C) LATSG; (D) TSGPG; (E) VLA; (F) VLATS; (G) VLATSGP; (H) VLATSGPG; (I) DKVF; (J) KVFR; (K) LDK; (L) LDKVF; (M) LDKVFR. 
Fig S1(A)

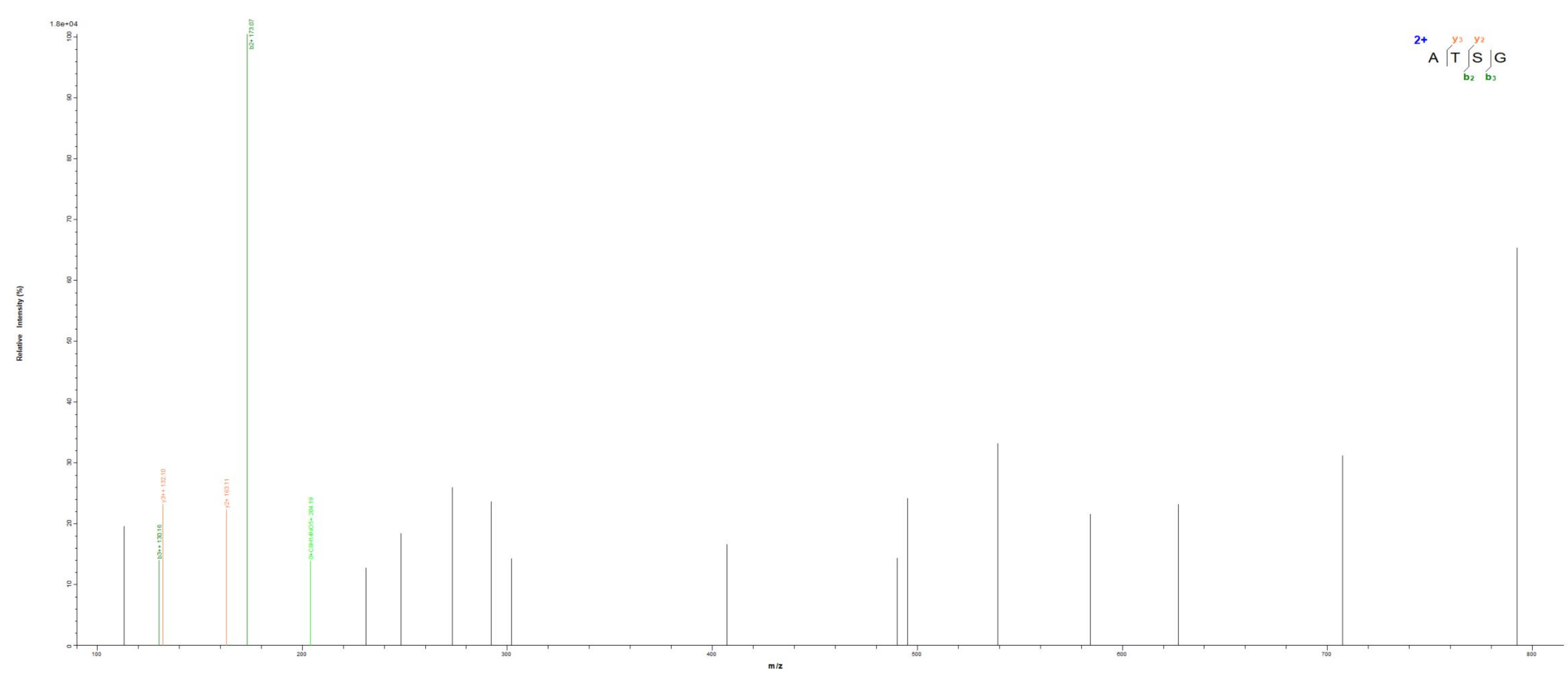


Fig S1 (B)

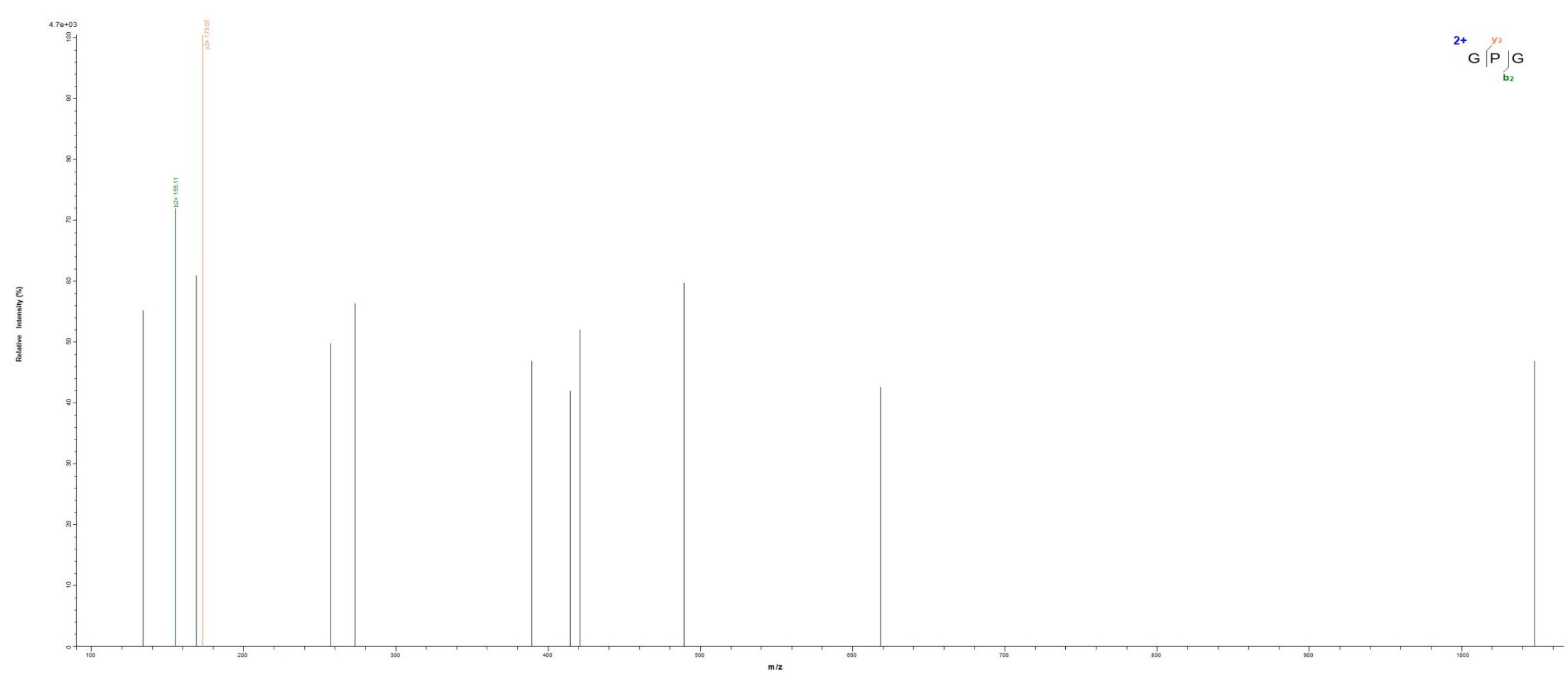


Fig S1 (C)

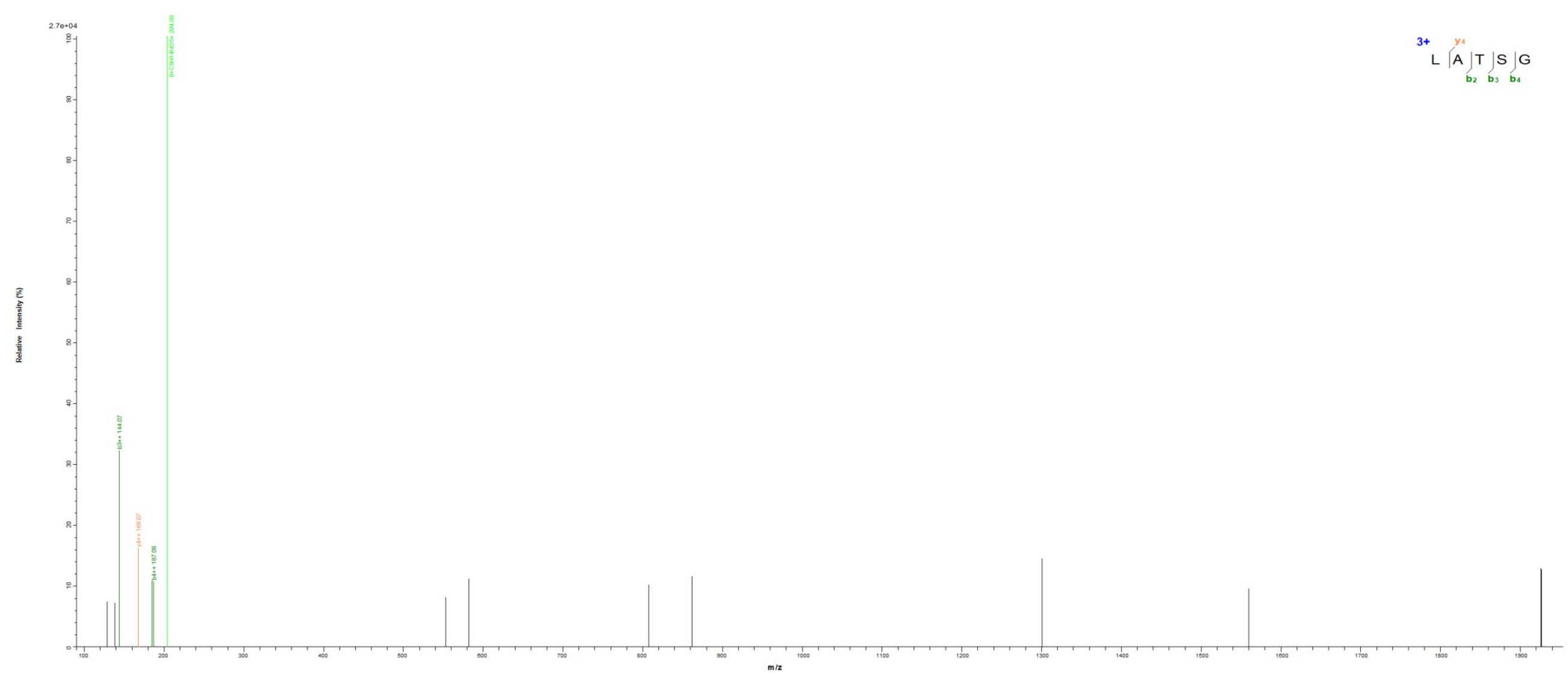


Fig S1 (D)

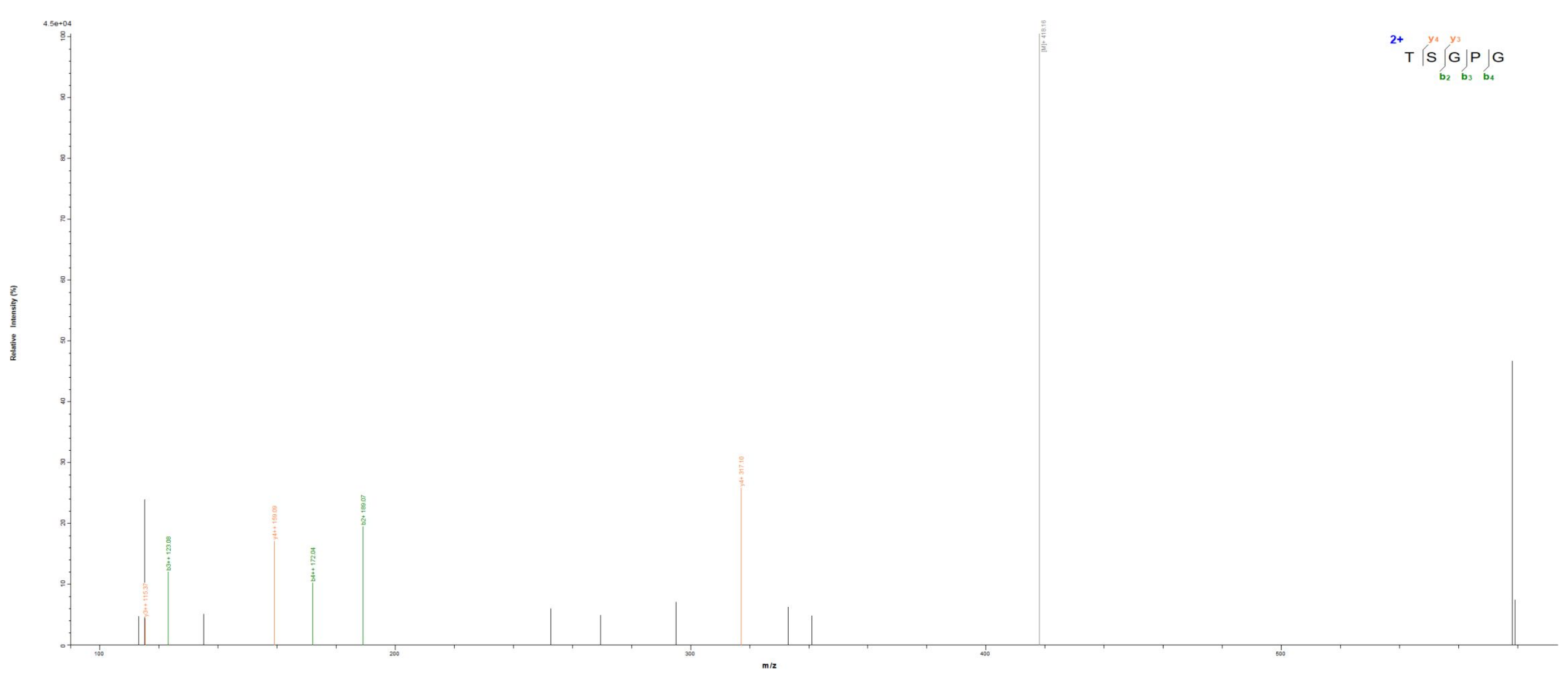


Fig S1 (E)

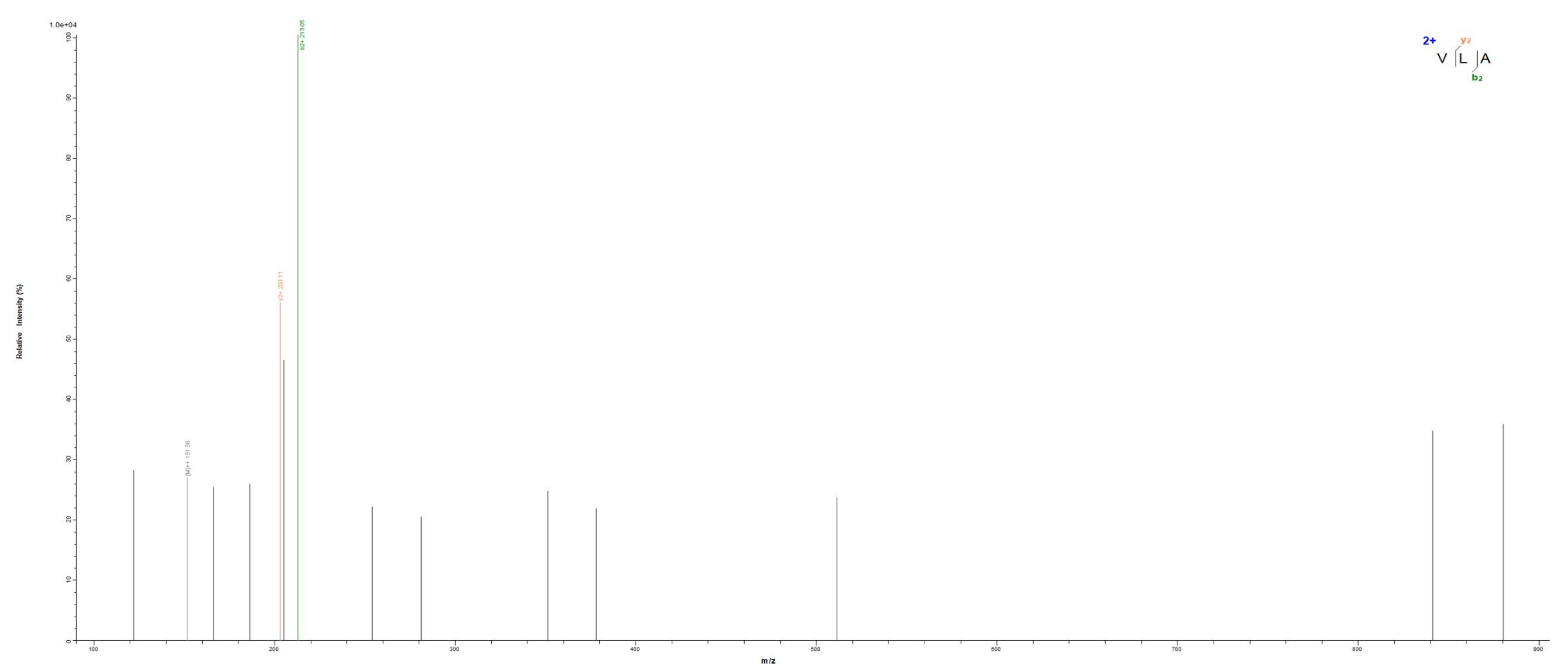


Fig S1 (F)

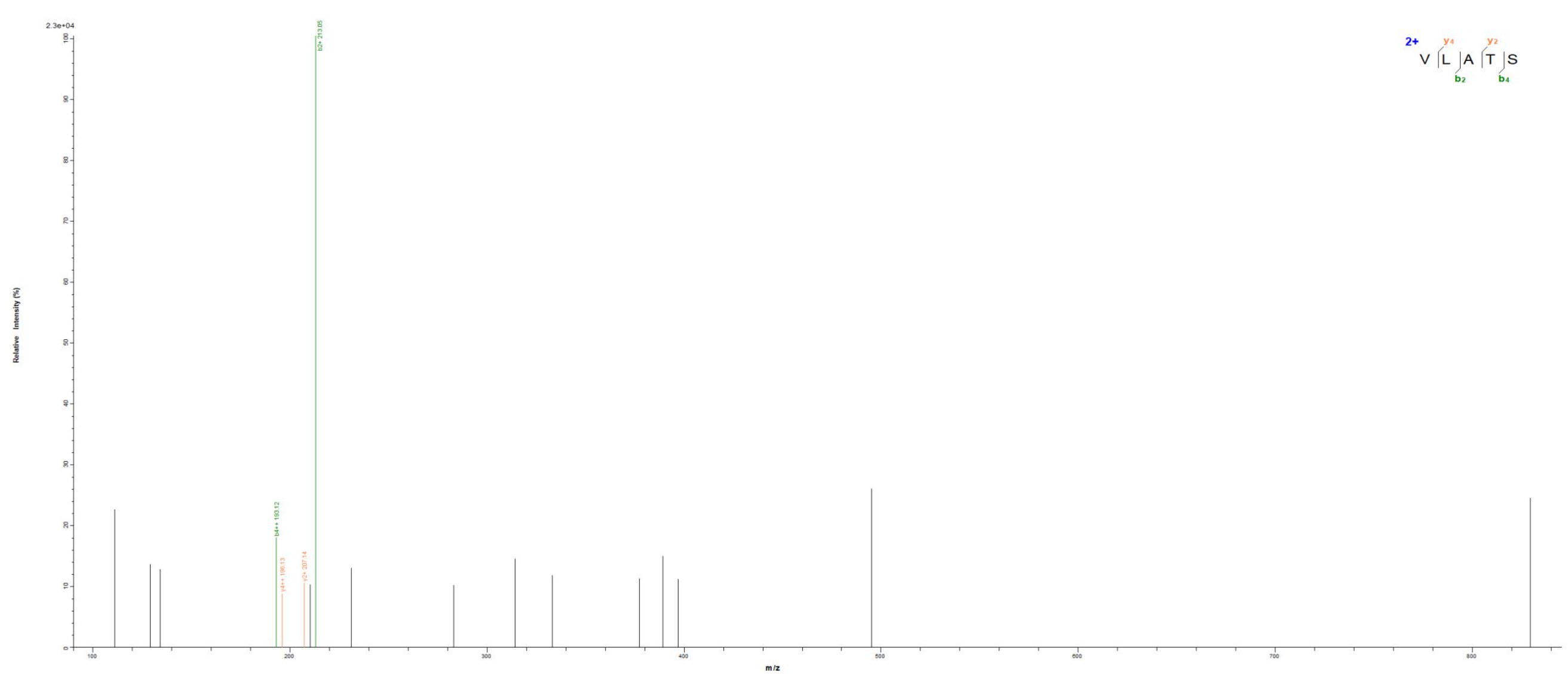


Fig S1 (G)

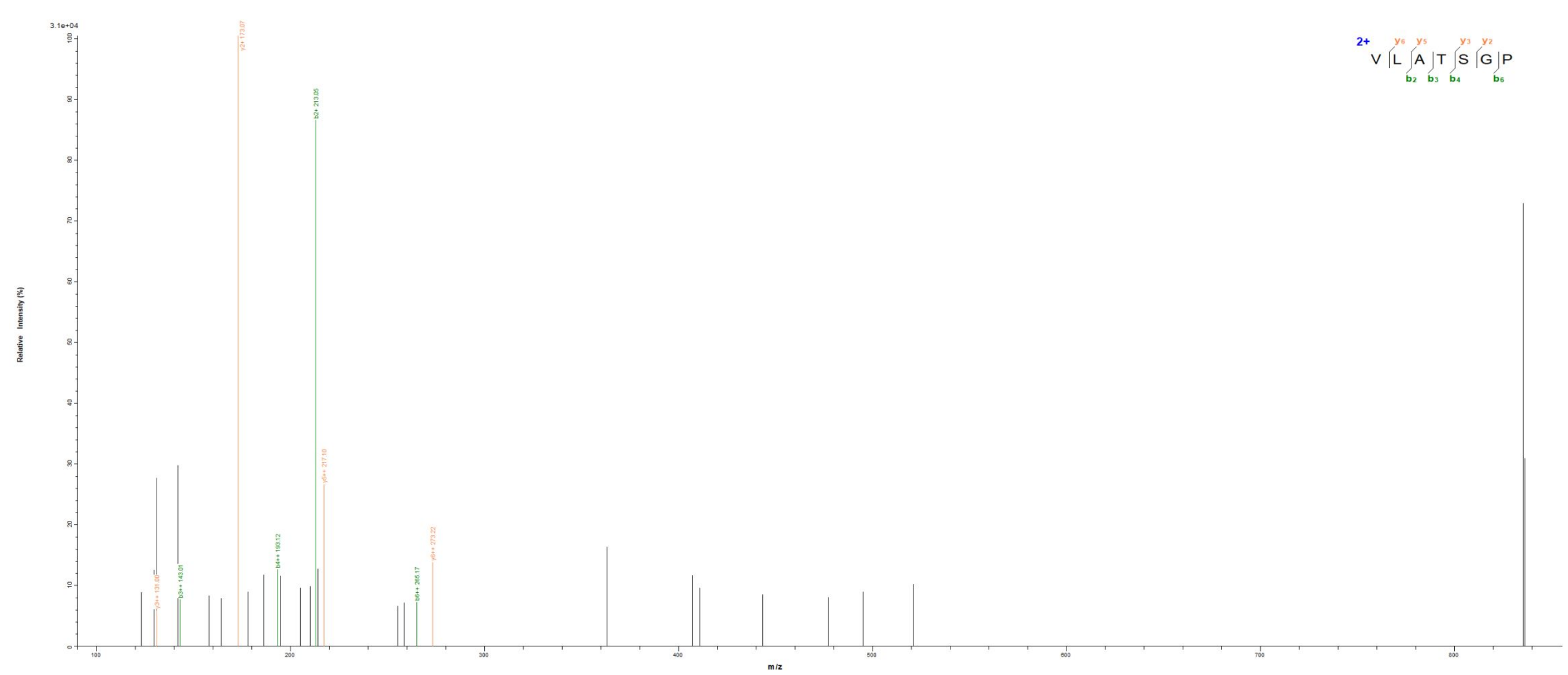


Fig S1 (H)

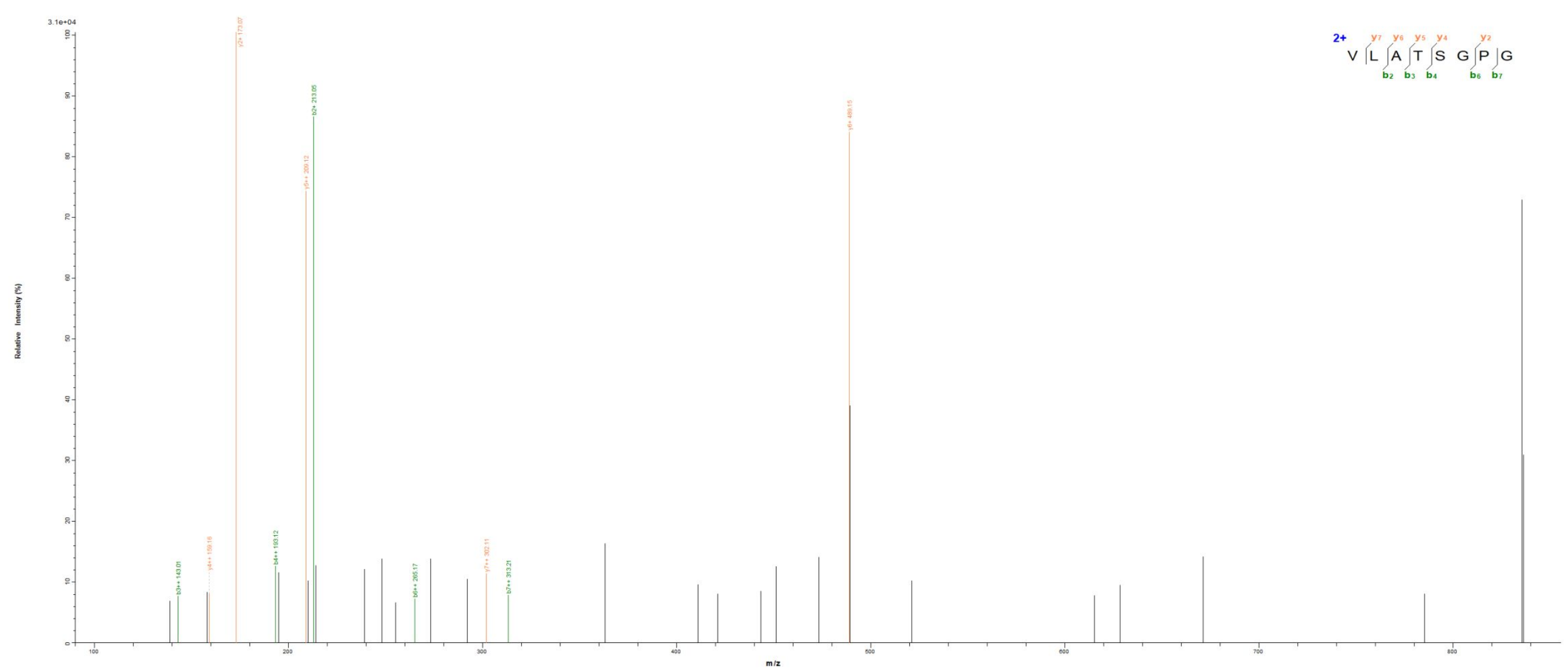


Fig S1 (I)

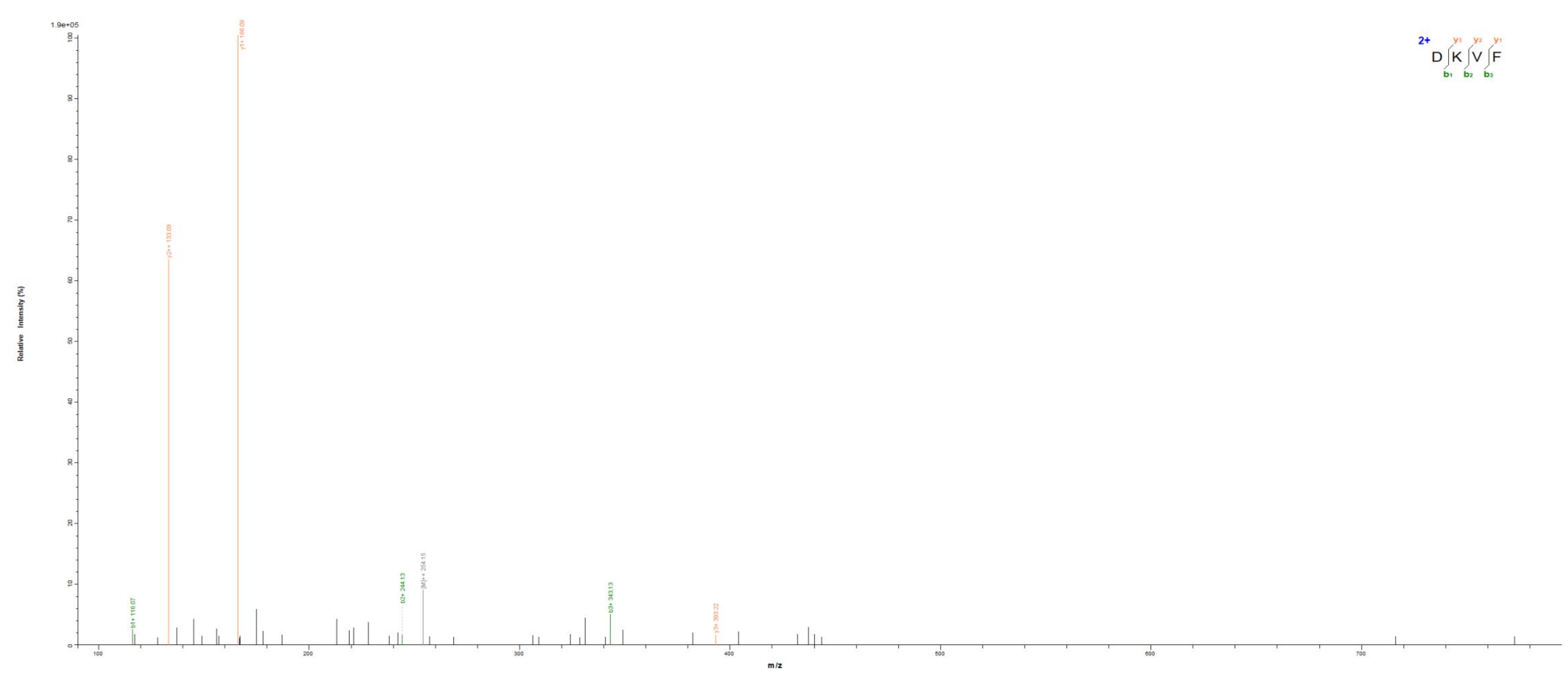


Fig S1 (J)

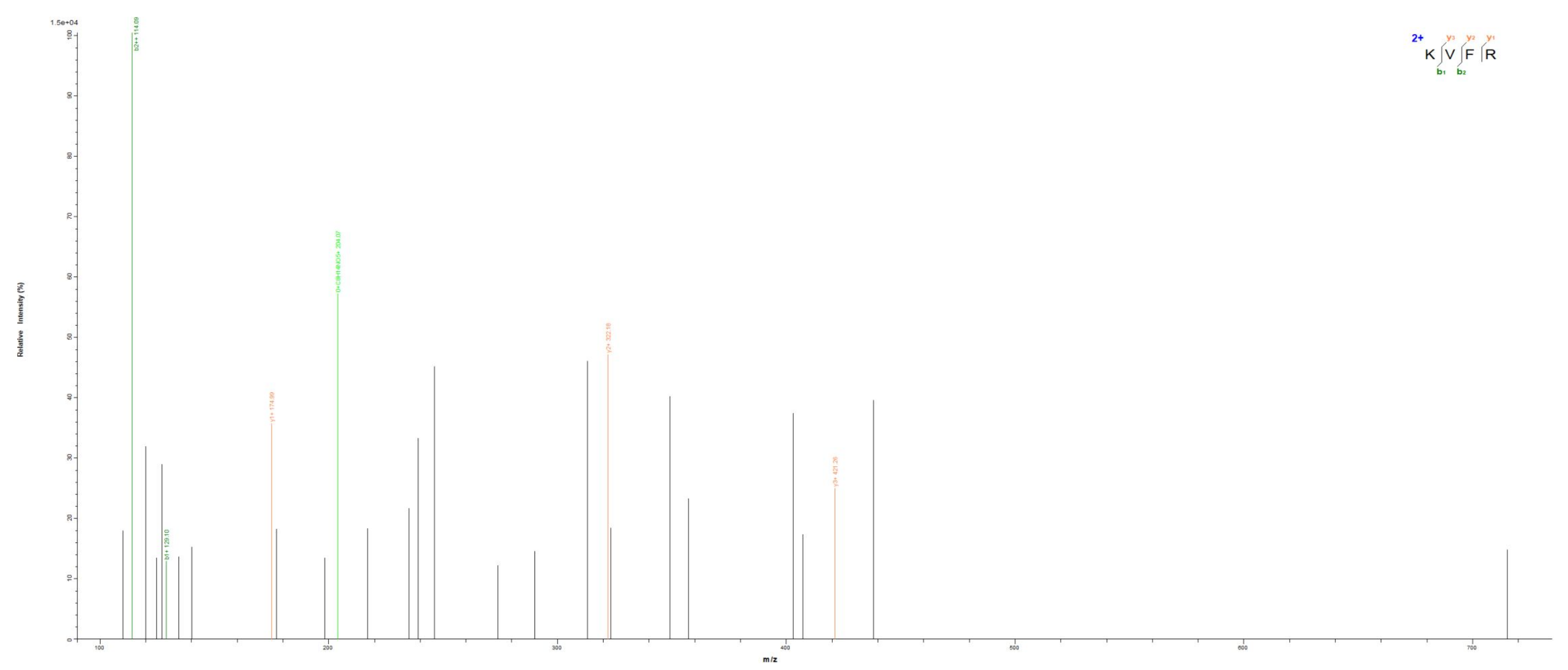


Fig S1 (K)

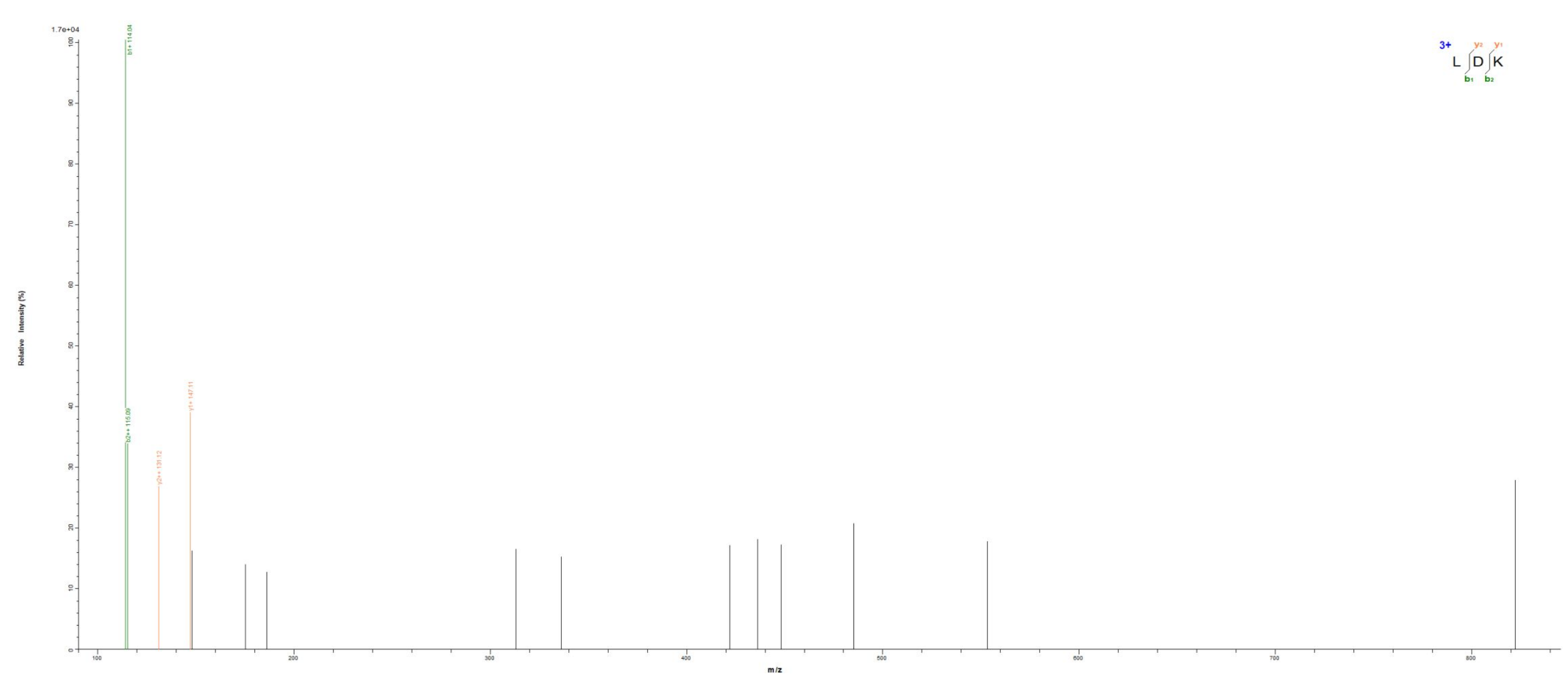


Fig S1 (L)

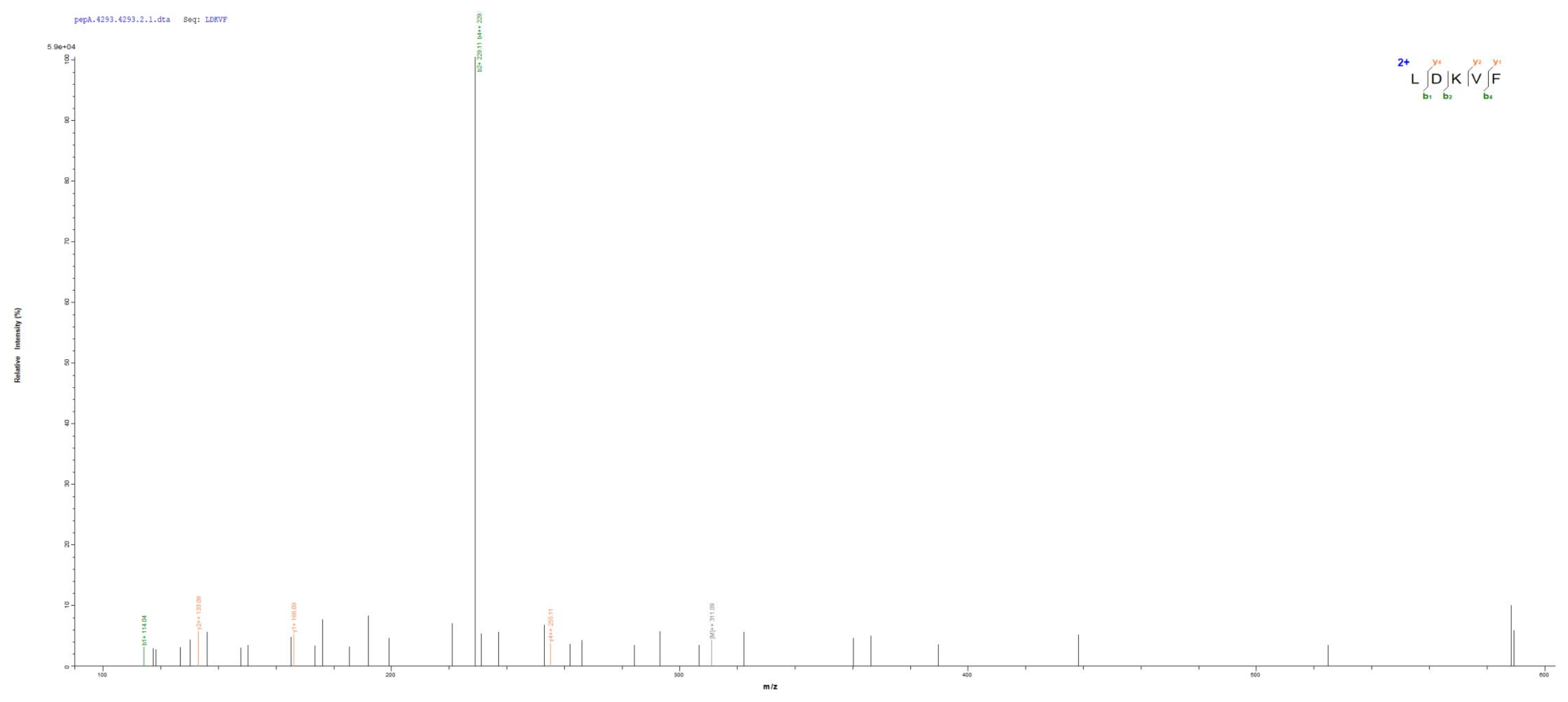


Fig S1 (M)

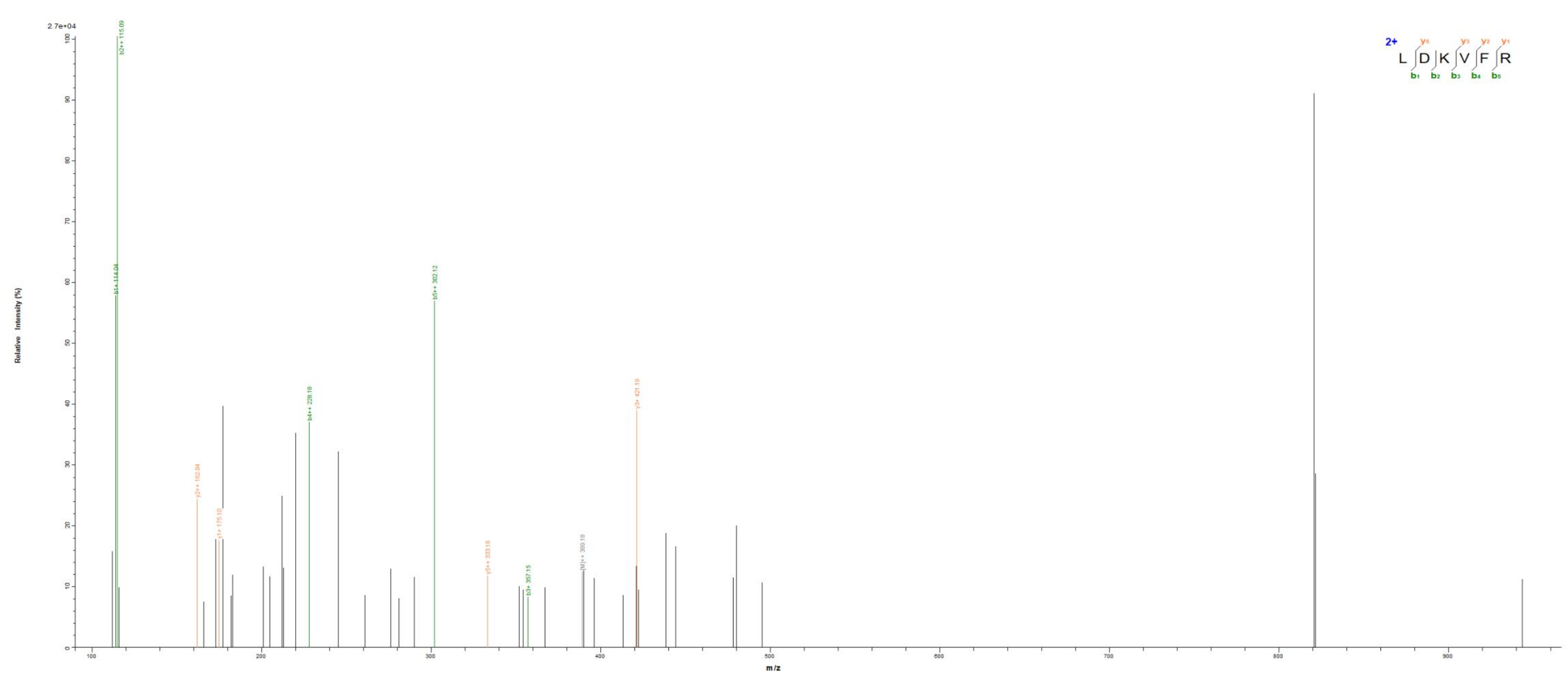

